Supporting information

\title{
Synthesis of nitrogen doped graphene films for lithium battery application
}

Arava Leela Mohana Reddy ${ }^{*}$, Anchal Srivastava ${ }^{1}$, Sanketh R. Gowda ${ }^{2}$, Gullapalli Hemtej ${ }^{1}$ Madan Dubey ${ }^{3}$ and Pulickel M. Ajayan ${ }^{1, *}$

${ }^{1}$ Department of Mechanical Engineering and Materials Science

${ }^{2}$ Department of Chemical and Biomolecular Engineering, Rice University, Houston, Texas 77005, USA

${ }^{3}$ U.S. Army Research Laboratory, 2800 Powder Mill Rd, Adelphi, MD 20783 USA

*To whom correspondence should be addressed: Email: ajayan@rice.edu, leela@rice.edu

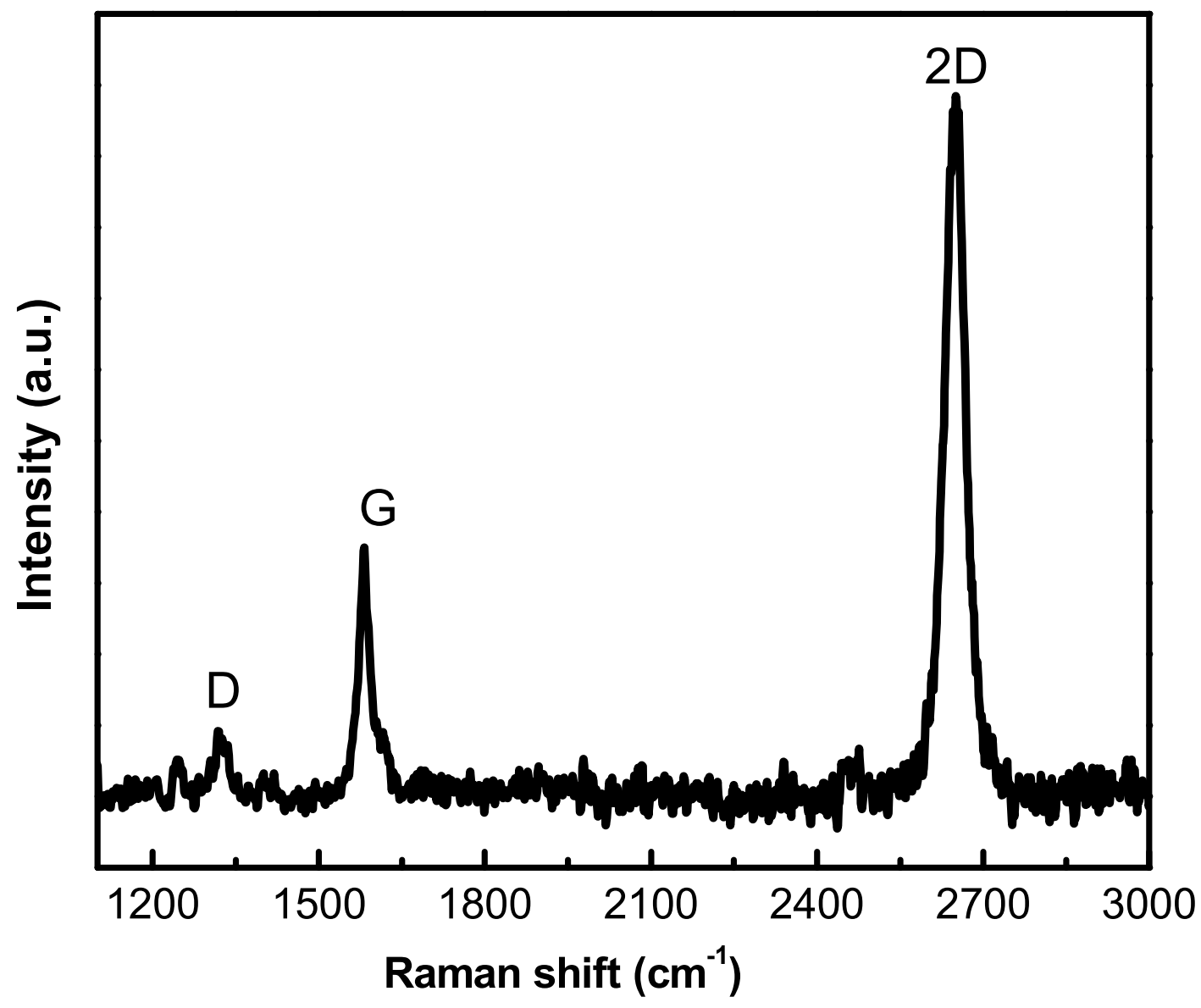

Figure S1: Raman spectra of the single layer pristine graphene grown on $\mathrm{Cu}$ foil using hexane precursors. 


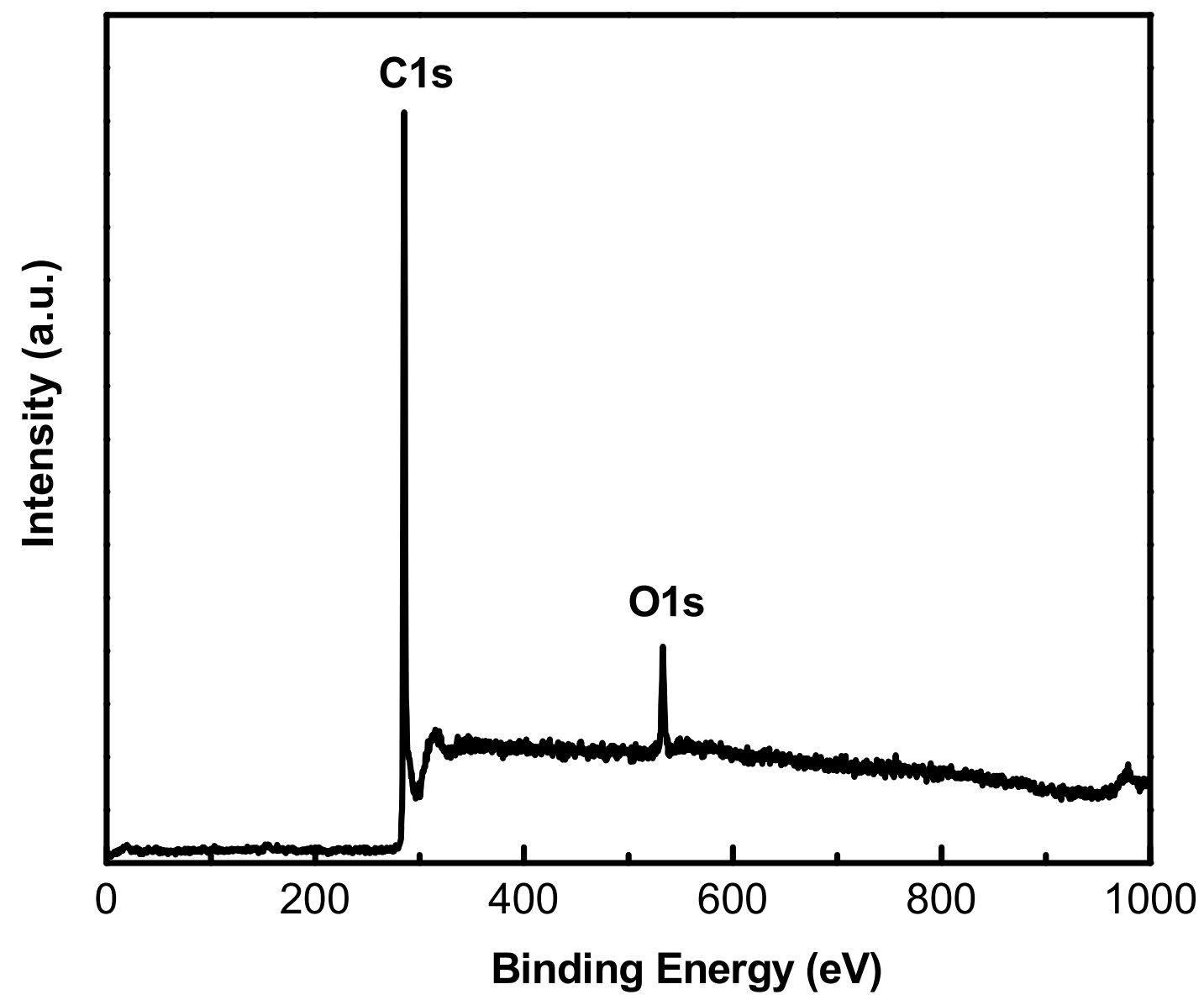

Figure S2: XPS spectra of the pristine graphene clearly show the presence of $\mathrm{C} 1 \mathrm{~s}$ and $\mathrm{O} 1 \mathrm{~s}$ spectra. 


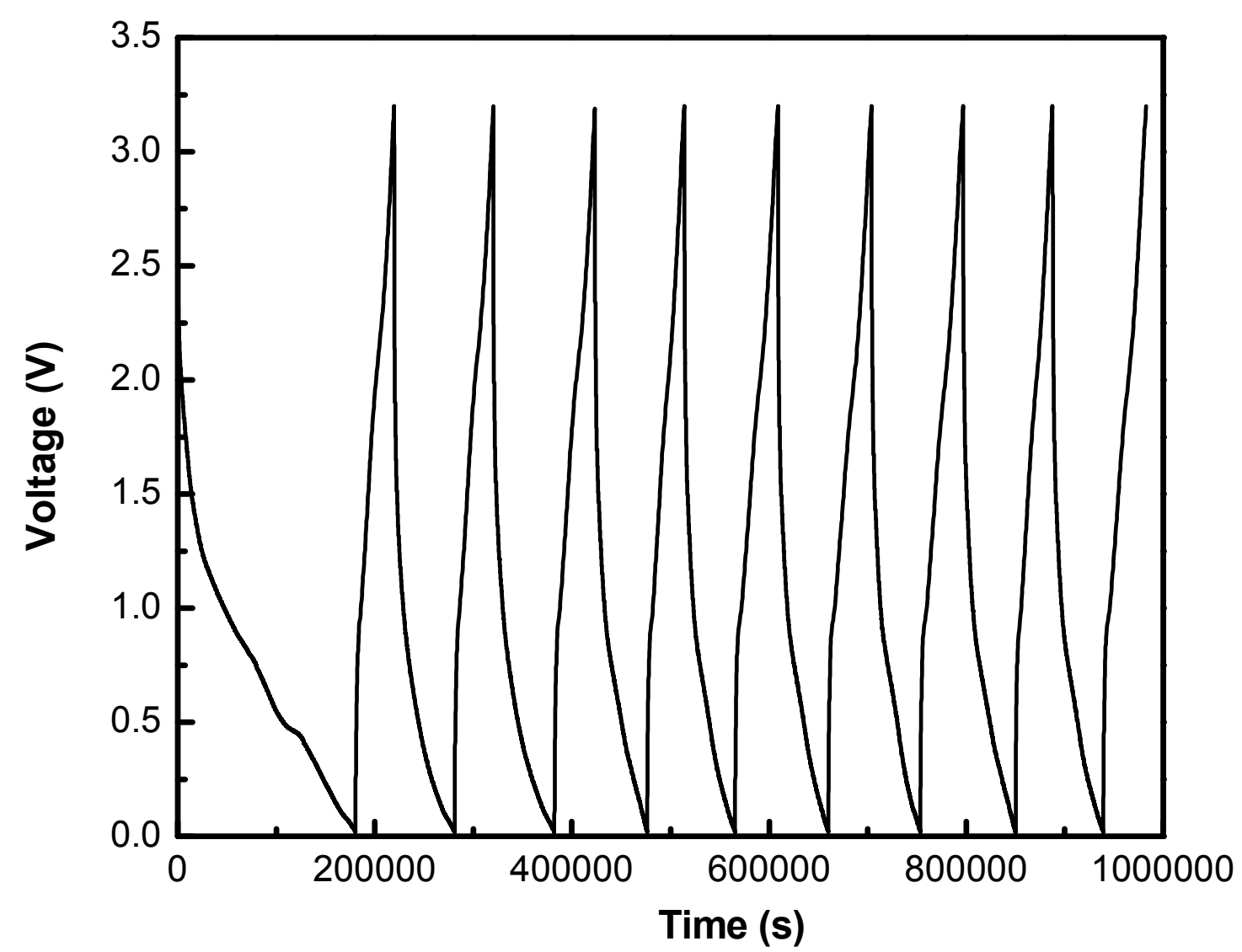

Figure S3: Voltage vs time profile of nitrogen doped graphene films grown on $\mathrm{Cu}$ foil, galvanostatically cycled in Li-half cells at a current rate of $5 \mu \mathrm{A} / \mathrm{cm}^{2}$ between $3.2 \mathrm{~V}$ and $0.02 \mathrm{~V}$ vs $\mathrm{Li}^{\prime} \mathrm{Li}^{+}$using $1 \mathrm{M}$ solution of $\mathrm{LiPF}_{6}$ in $1: 1(\mathrm{v} / \mathrm{v})$ mixture of ethylene carbonate $(\mathrm{EC})$ and dimethyl carbonate (DMC) as the electrolyte. 


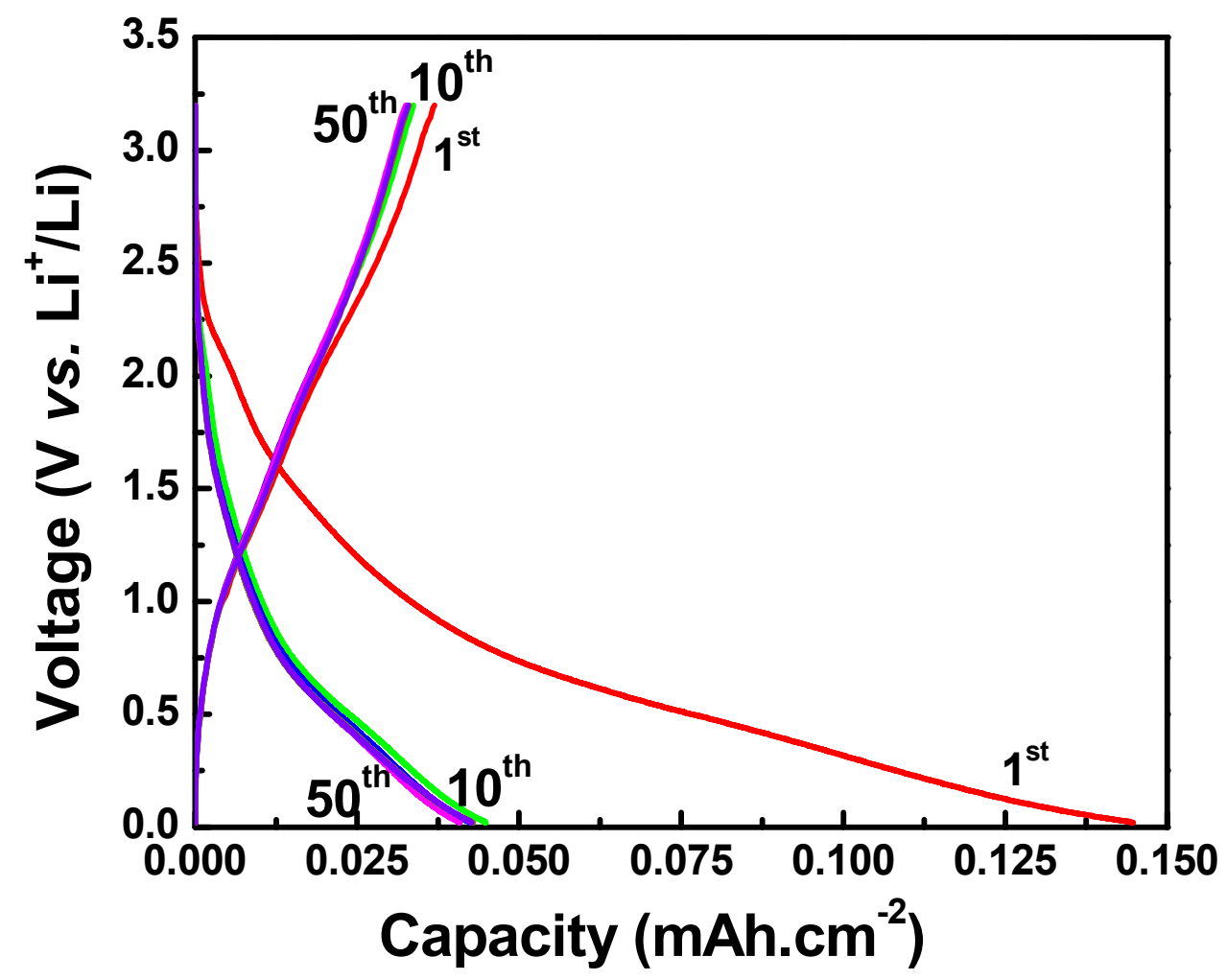

Figure S4: Electrochemical performance of pristine graphene films grown on $\mathrm{Cu}$ foil, galvanostatically cycled in Li-half cells at a current rate of $5 \mu \mathrm{A} / \mathrm{cm}^{2}$ between $3.2 \mathrm{~V}$ and $0.02 \mathrm{~V}$ vs $\mathrm{Li} / \mathrm{Li}^{+}$using $1 \mathrm{M}$ solution of $\mathrm{LiPF}_{6}$ in $1: 1(\mathrm{v} / \mathrm{v})$ mixture of ethylene carbonate $(\mathrm{EC})$ and dimethyl carbonate (DMC) as the electrolyte. 